\title{
Studies on the Polymerization of Methyl Methacrylate with Butylmagnesium Chloride by the Aid of Totally Deuterated Monomer-Structures of Polymerization Products and Fate of Initiator
}

\author{
Koichi UTE, Tatsuki KITAYAMA, and Koichi HATADA \\ Department of Chemistry, Faculty of Engineering Science, Osaka University, \\ Toyonaka, Osaka 560, Japan
}

(Received July 8, 1985)

\begin{abstract}
Totally deuterated methyl methacrylate (MMA- $d_{8}$ ) was polymerized by $\mathrm{C}_{4} \mathrm{H}_{9} \mathrm{MgCl}$ in toluene at $-78^{\circ} \mathrm{C}$, and the resulting polymer and oligomer were analyzed by ${ }^{1} \mathrm{H}$ NMR spectroscopy. The polymer and oligomer was found to contain butyl pentadeuteroisopropenyl ketone $\left(\right.$ BIPK $\left.-d_{5}\right)$ units. The ketone was formed by the addition of the initiator onto the carbonyl group of the monomer. The content of BIPK- $d_{5}$ units in the polymer and oligomer was found to be 0.3 and 0.4 per chain, respectively. FD- and EI-mass spectra of the fractionated oligo(MMA)s indicated that most of the BIPK units were located at their terminating chain ends. Structures which were produced by intramolecular cyclization and by carbonyl addition of propagating anions onto MMA or BIPK were found at the end of the oligomer chain, but the amounts of these structures were at most $10 \%$ of the chain. The fate of the initiator during the polymerization was clarified for the most part. From the results, the mechanism of polymerization is discussed in some detail.
\end{abstract}

KEY WORDS Mechanism of Anionic Polymerization / Poly(methyl methacrylate) / Totally Deuterated Methyl Methacrylate / Butylmagnesium Chloride / $t$-Butylmagnesium Chloride / NMR Spectroscopy / Mass Spectroscopy / Intramolecular Cyclization / Butyl Isopropenyl Ketone / Grignard Reagent /

Many papers have been published on the polymerization of methacrylates by organomagnesium compounds since Goode ${ }^{1}$ and Nishioka ${ }^{2}$ reported the polymerization of methyl methacrylate (MMA) by Grignard reagents in 1960. In several review articles, ${ }^{3-5}$ the polymerizations of methacrylates by organomagnesium compounds have been summarized and the mechanism of polymerization is discussed in some detail.

However, there still exist some ambiguities regarding the polymerization, particularly in the structure of the polymer, efficiency of initiator, and mechanism of polymerization. The complexity of the factors affecting the polymerization has prevented a clear understanding of the polymerization reaction, and the molecular weight and its distribution of the polymer cannot be fully controlled.

Several recent studies have dealt with the effects of temperature and amount of THF of $\mathrm{MgX}_{2}$ on the stereoregularity and molecular weight of the resulting polymer. ${ }^{6-8}$ Allen and his coworkers ${ }^{9}$ studied the mechanism of the polymerization of MMA by butylmagnesium compounds in toluene-tetrahydrofuran (THF) mixtures mainly by kinetic methods.

Chemical analysis of the reaction products is another approach to the mechanism of polymerization. Goode and his coworkers ${ }^{10}$ 
studied the initiation and termination processes in the polymerization of MMA by tritium-labeled phenylmagnesium bromide through a detailed analysis of the low molecular weight products of polymerization. Yasuda and his coworkers ${ }^{11}$ investigated the elementary steps of the polymerization reaction by butylmagnesium bromide. Bateup and Allen ${ }^{12}$ determined the amounts of the unreacted initiator and $\mathrm{CH}_{3} \mathrm{OMg}$ - formed during the polymerization of MMA by butylmagnesium bromide in toluene-THF mixtures.

The present authors have developed a new method for understanding the mechanism of polymerization using totally deuterated monomers. ${ }^{13-18}$ When a deuterated monomer is polymerized by an undeuterated initiator, the fragments of the initiator and/or the terminating reagent incorporated in the polymer or oligomer chain can be easily detected by ${ }^{1} \mathrm{H}$ NMR spectroscopy without disturbance from signals due to monomeric units in the chain. In this work, we extended this method to the polymerization of MMA by butylmagnesium chloride $\left(\mathrm{C}_{4} \mathrm{H}_{9} \mathrm{MgCl}\right)$ to elucidate the structures of the polymerization products and the fate of the initiator during the polymerization.

\section{EXPERIMENTAL}

Totally deuterated methyl methacrylate $\left(\mathrm{MMA}-d_{8}\right)$ was prepared by the procedure reported previously. ${ }^{15}$ Butylmagnesium chloride $\left(\mathrm{C}_{4} \mathrm{H}_{9} \mathrm{MgCl}\right)$ was prepared from butyl chloride and magnesium metal in diethyl ether under a nitrogen atmosphere. The concentration of the solution was found to be $0.86 \mathrm{~mol}-$ $1^{-1}$ by titration with sec-butanol, using 9,10 phenanthroline as an indicator. ${ }^{19}$

Polymerization was carried out in toluene in a glass ampoule under a dry nitrogen atmosphere. The polymerization was initiated by adding the monomer slowly to a mixture of toluene and the $\mathrm{C}_{4} \mathrm{H}_{9} \mathrm{MgCl}$ solution cooled to $-78^{\circ} \mathrm{C}$. Unless otherwise noted, the polymer- ization was stopped by adding a small amount of methanol at the polymerization temperature, and the mixture was poured into a large amount of methanol. The precipitated polymer was filtered, washed thoroughly with methanol and dried in vacuo at $60^{\circ} \mathrm{C}$ for $2 \mathrm{~h}$. The filtrate and washings were combined and evaporated to dryness to recover the methanol-soluble oligomer. The residue obtained was freeze-dried from the benzene solution.

${ }^{1} \mathrm{H}$ NMR spectra of $\mathrm{P}\left(\mathrm{MMA}-d_{8}\right)$ s were taken in nitrobenzene- $d_{5}$ at $110^{\circ} \mathrm{C}$ or in chloroform- $d_{1}$ at $60^{\circ} \mathrm{C} .{ }^{13} \mathrm{C}$ NMR spectra of the oligomer of MMA were measured in chloroform- $d_{1}$ at $55^{\circ} \mathrm{C}$. The NMR instruments used were JNM FX100 (JEOL) and JNM GX500 (JEOL) spectrometers operated at 100 and $500 \mathrm{MHz}$, respectively, for the ${ }^{1} \mathrm{H}$ spectra. The hydrogen content of a sample was determined from the relative intensity of the signal of interest to the signal due to the remaining protons in the nitrobenzene- $d_{5}$ used as a solvent. The absolute intensity of the latter signal was measured by a precision coaxial tubing method. ${ }^{20)}$ Spin-lattice relaxation time, $T_{1}$, was measured by the inversion recovery method.

Field desorbtion (FD-) and electron impact (EI-) mass spectra were measured on a JMS01SG-2 (JEOL) mass spectrometer.

The number average molecular weight was determined in chloroform at $40^{\circ} \mathrm{C}$ or in toluene at $60^{\circ} \mathrm{C}$ by a Hitachi 117 vapor pressure osmometer (VPO).

Fractionation of the oligomers was performed on a TRIROTAR II (JASCO) high performance liquid chromatograph with a column packed with polystyrene gel (maximum porosity 3000) and an RI-162 (JASCO) refractive index detector. Chloroform was employed as an eluent.

Thermal decompositions of the polymer and oligomer were performed by heating at $300-$ $350^{\circ} \mathrm{C}$ under vacuum. The products were collected in a reservoir cooled in a liquid nitrogen bath and analyzed by gas-liquid chromatography. 
Table I. Polymerization of MMA and MMA- $d_{8}$ by $\mathrm{C}_{4} \mathrm{H}_{9} \mathrm{MgCl}$ in toluene at $-78^{\circ} \mathrm{C}$ for $72 \mathrm{~h}^{\mathrm{a}}$

\begin{tabular}{|c|c|c|c|c|c|c|c|}
\hline \multirow{3}{*}{ Entry } & \multirow{3}{*}{\multicolumn{2}{|c|}{$\begin{array}{l}\text { Monomer } \\
\mathrm{mmol}\end{array}$}} & \multirow{3}{*}{$\begin{array}{l}\text { Termi- } \\
\text { nating } \\
\text { reagent }\end{array}$} & \multicolumn{2}{|c|}{ Polymer ${ }^{\mathrm{b}}$} & \multicolumn{2}{|c|}{ Oligomer ${ }^{\mathrm{c}}$} \\
\hline & & & & Yield & & Yield & \\
\hline & & & & $\%$ & & $\%$ & \\
\hline $\mathrm{D} / \mathrm{h}$ & MMA- $d_{8}$ & 5.39 & $\mathrm{CH}_{3} \mathrm{OH}$ & 70.3 & 12,000 & 29.4 & 989 \\
\hline$D / d$ & MMA- $d_{8}$ & 5.45 & $\mathrm{CD}_{3} \mathrm{OD}$ & 71.0 & 13,500 & 28.2 & 940 \\
\hline $\mathrm{H} / \mathrm{h}$ & MMA & 5.02 & $\mathrm{CH}_{3} \mathrm{OH}$ & $67.1^{\mathrm{d}}$ & 10,200 & 30.0 & 940 \\
\hline
\end{tabular}

a Toluene $5.0 \mathrm{ml}, \mathrm{C}_{4} \mathrm{H}_{9} \mathrm{MgCl} 0.518 \mathrm{mmol}$.

b Methanol-insoluble part.

c Methanol-soluble part.

d The polymer had a tacticity of $\mathrm{I}: \mathrm{H}: \mathrm{S}=31: 18: 51$, and could be fractionated into syndiotactic $(\mathrm{I}: \mathrm{H}: \mathrm{S}=5: 25: 70)$ and isotactic $(\mathrm{I}: \mathrm{H}: \mathrm{S}=57: 12: 31)$ parts by the competitive adsorbtion method developed by Miyamoto et al. ${ }^{30}$ However, in this work, all the polymers were analyzed without fractionation.

For the quantitative determination of unreacted $\mathrm{C}_{4} \mathrm{H}_{9} \mathrm{MgCl}$ and butyl isopropenyl ketone formed during the polymerization, the reaction mixture was quenched by acetic acid and subjected to gas-liquid chromatographic analysis. The amount of the unreacted initiator was determined as butane. A shimadzu GC-8A chromatograph equipped with a PEG-20M column $(300 \mathrm{~cm} \times 0.3 \mathrm{~cm})$ and an FID detector was used.

\section{RESULTS}

Structures of MMA- and Ketone-Ended Polymer and Oligomer Molecules

Polymerizations of MMA and MMA- $d_{8}$ were carried out with $\mathrm{C}_{4} \mathrm{H}_{9} \mathrm{MgCl}$ in toluene at $-78^{\circ} \mathrm{C}$ for $72 \mathrm{~h}$. The results are shown in Table I. The polymerizations of MMA- $d_{8}$ were stopped by quenching the mixture with $\mathrm{CH}_{3}$ $\mathrm{OH}$ (entry $\mathrm{D} / \mathrm{h}$ ) and $\mathrm{CD}_{3} \mathrm{OD}$ (entry $\mathrm{D} / \mathrm{d}$ ), respectively. The polymerization of MMA was quenched by $\mathrm{CH}_{3} \mathrm{OH}$ (entry $\mathrm{H} / \mathrm{h}$ ). The results of these three polymerizations were similar in yield and molecular weight. In all the polymerizations, the reaction products contained about $70 \%$ methanol-insoluble polymer and about $30 \%$ methanol-soluble oligomer.

The ${ }^{1} \mathrm{H}$ NMR spectra of the polymer and oligomer of MMA- $d_{8}$ (Polymer-D/h and Oligomer-D/h in Table I) are illustrated in Figure 1. The signals at 0.8 and $1.1 \mathrm{ppm}$ were assigned to the methyl and methylene protons of butyl groups, respectively, which originally came from the initiator. The triplet at 2.40 ppm is attributed to the carbonyl methylene protons of butyl pentadeuteroisopropenyl ketone $\left(\mathrm{BIPK}-d_{5}\right)$ units incorporated into the polymer or oligomer chain. ${ }^{15}$ BIPK- $d_{5}$ should be formed through attack of the initiator on the carbonyl group of the monomer.

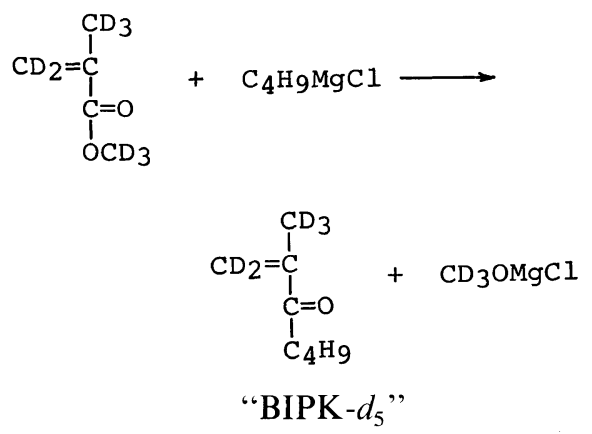

The presence of the ketone unit in the chain was also evidenced by the thermal decomposition of the polymer or oligomer followed by gas chromatographic analysis.

The singlets at 2.45 and $2.57 \mathrm{ppm}$ were assigned to the methine protons introduced 


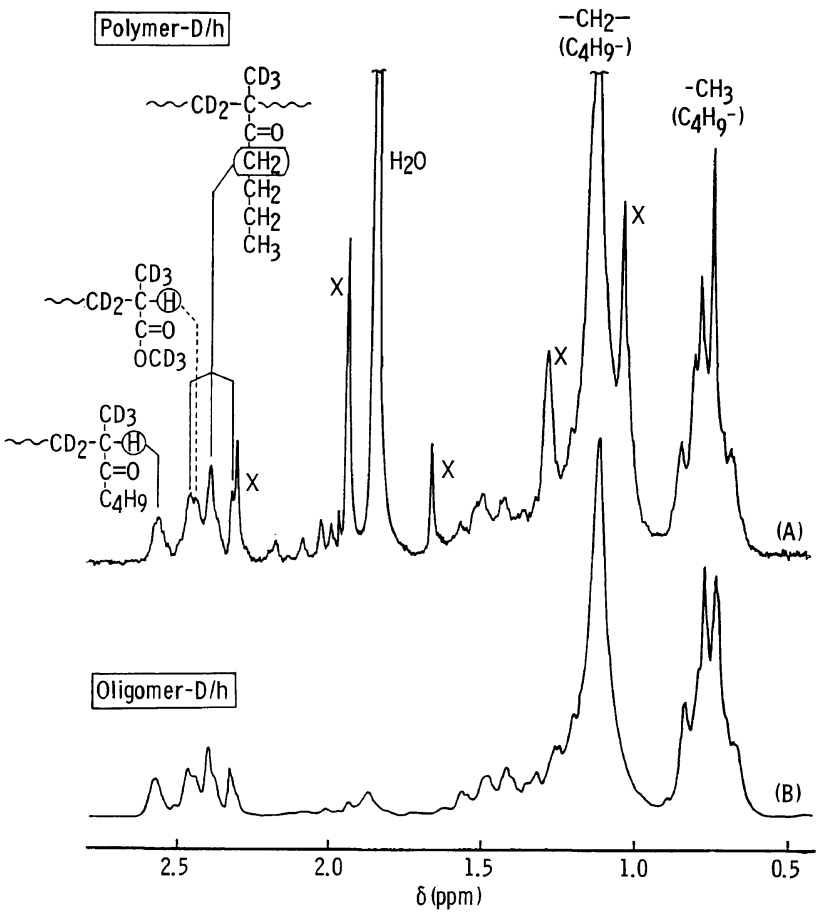

Figure 1. ${ }^{1} \mathrm{H}$ NMR spectra of the polymer and oligomer of MMA- $d_{8}$ prepared by $\mathrm{C}_{4} \mathrm{H}_{9} \mathrm{MgCl}$ in toluene at $-78^{\circ} \mathrm{C}$. The signals labeled $\mathrm{X}$ are due to the remaining protons in the monomer units.

into the $\omega$-ends ${ }^{* 1}$ from the terminating reagent $\left(\mathrm{CH}_{3} \mathrm{OH}\right)$. The former, though it overlaps with the triplet at $2.40 \mathrm{ppm}$, is assigned to the methine proton in the terminal MMA unit. The latter is attributed to the methine proton attached to the BIPK- $d_{5}$ unit located at the $\omega$ end. ${ }^{18 .}$ The abbreviations "MMA-H" and "BIPK-H" are used hereinafter to denote these terminal methine protons.

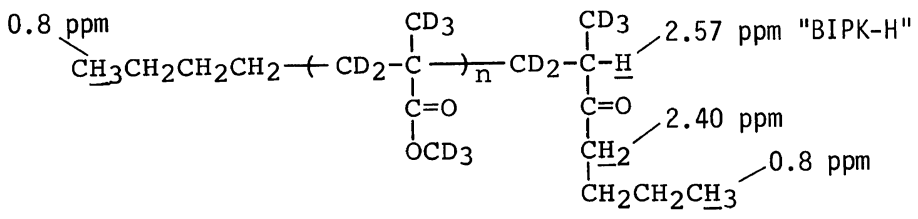

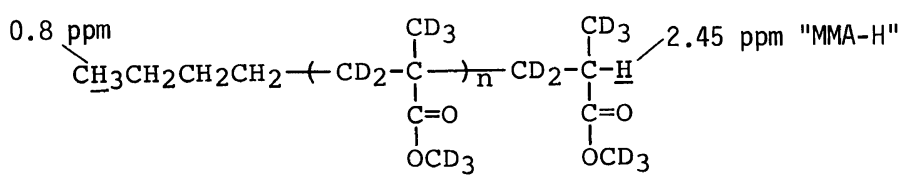

*1 IUPAC Commission on Macromolecular Nomenclature recommended (1983) that a nomenclature " $\alpha-X-\omega-Y$ poly(A)" should be used for the polymer "X-(A) $)_{n}-\mathrm{Y}$ ". Following this recommendation, the present authors propose to use the designations " $\alpha$-end" to express the beginning of polymer chain and " $\omega$-end" to express the terminating end of the chain. 


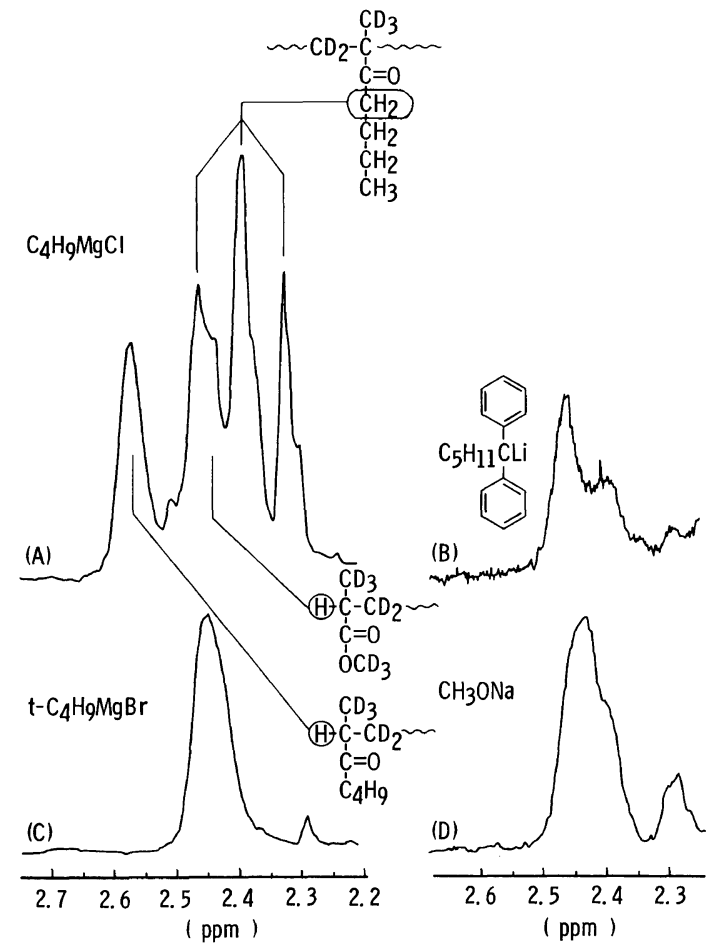

Figure 2. ${ }^{1} \mathrm{H}$ NMR spectra of polymers prepared by $\mathrm{C}_{4} \mathrm{H}_{9} \mathrm{MgCl}$ in toluene at $-78^{\circ} \mathrm{C}(\mathrm{A}), 1,1$-diphenylhexyllithium in $\mathrm{THF}$ at $-78^{\circ} \mathrm{C}(\mathrm{B}), t-\mathrm{C}_{4} \mathrm{H}_{9} \mathrm{MgBr}$ in toluene at $-78 \mathrm{C}(\mathrm{C})$, and $\mathrm{CH}_{3} \mathrm{ONa}$ in diethyl ether at $50^{\circ} \mathrm{C}(\mathrm{D})$.

To confirm these assignments, the ${ }^{1} \mathrm{H}$ NMR spectra of $\mathrm{P}\left(\mathrm{MMA}-d_{8}\right)$ s obtained by several kinds of initiators were inspected as shown in Figure 2. The polymer obtained by $\mathrm{CH}_{3} \mathrm{ONa}$ must contain no ketone unit even if carbonyl addition occurs, and all the terminal methine protons should be MMA-H ( $c f$. Figure 2D). In the polymerization by 1,1-diphenylhexyllithium ( $c f$. Figure 2B) or $t-\mathrm{C}_{4} \mathrm{H}_{9} \mathrm{MgBr}$ ( $c f$. Figure. $2 \mathrm{C}$ ), the initiator hardly attacks the carbonyl group of MMA and the reaction is living. ${ }^{21-23}$ The P(MMA- $\left.d_{8}\right)$ s obtained by these three initiators showed rather broad signals ${ }^{* 2}$ at about $2.45 \mathrm{ppm}$, but not at $2.57 \mathrm{ppm}$ (Figures 2B, 2C, and 2D). Thus, the signal at about $2.45 \mathrm{ppm}$ should be assigned to MMA-H, and the one at $2.57 \mathrm{ppm}$ to BIPK-H.

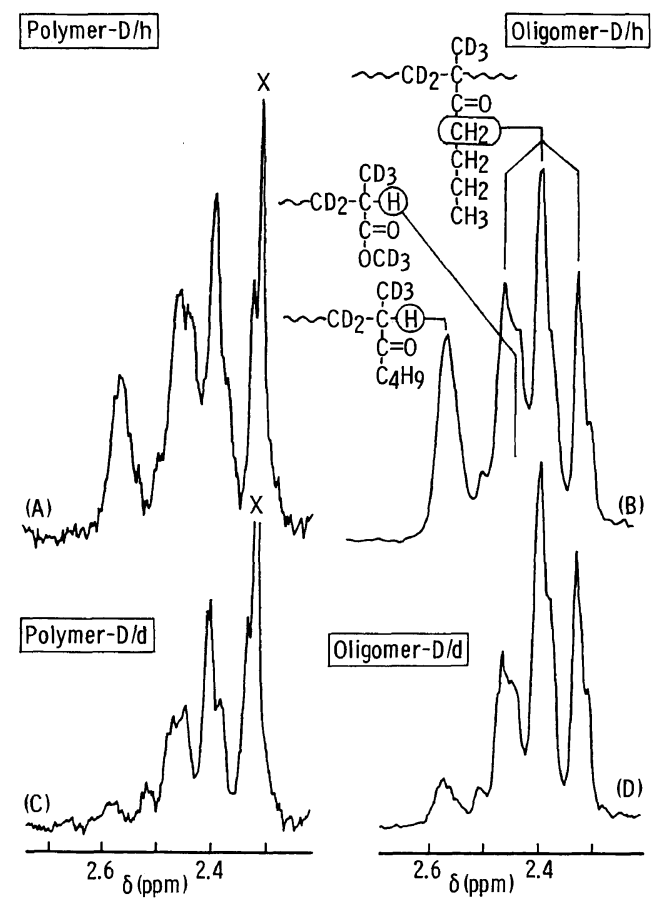

Figure 3. ${ }^{1} \mathrm{H}$ NMR spectra of the polymer and oligomer of $\mathrm{MMA}-d_{8}$ formed in the polymerization by $\mathrm{C}_{4} \mathrm{H}_{9} \mathrm{MgCl}$ terminated with $\mathrm{CH}_{3} \mathrm{OH}$ (A), (B), or $\mathrm{CD}_{3} \mathrm{OD}(\mathrm{C})$, (D). $\mathrm{X}$, signals due to the remaining protons in the monomer units. Reproduced with permission from ref 18. Copyright 1984, Polymer Journal.

Table II. ${ }^{1} \mathrm{H}$ NMR Signal intensities for the polymer and oligomer of MMA- $d_{8}$ prepared by $\mathrm{C}_{4} \mathrm{H}_{9} \mathrm{MgCl}$ in toluene at $-78^{\circ} \mathrm{C}$ for $72 \mathrm{~h}$

\begin{tabular}{|c|c|c|c|}
\hline \multirow{2}{*}{ Sample } & \multicolumn{3}{|c|}{$\begin{array}{c}\text { Amount } \\
\left(10^{-3} \text { g-hydrogen } / \text { g-sample }\right)\end{array}$} \\
\hline & $\begin{array}{l}\mathrm{CH}_{3}^{-} \\
\text {(butyl) }\end{array}$ & $\begin{array}{c}-\mathrm{CH}_{2} \mathrm{CO}- \\
(\mathrm{BIPK}) \\
+ \text { MMA-H }\end{array}$ & BIPK-H \\
\hline Polymer-D/h & 0.3214 & 0.0898 & 0.0214 \\
\hline Polymer-D/d & 0.2897 & 0.0491 & 0.0034 \\
\hline Oligomer-D/h & $4.949^{\mathrm{a}}$ & 1.280 & 0.359 \\
\hline Oligomer-D/d & $4.814^{\mathrm{a}}$ & 0.896 & 0.065 \\
\hline
\end{tabular}

a Ten percent of these values are due to the butyl group of dibutylisopropenylcarbinol included in the oligomer as mentioned in Results.

*2 Further split, which seems due to the difference of stereostructure at the $\omega$-end, was observed in the ${ }^{1} \mathrm{H}$ NMR spectra measured at a higher magnetic field. 
Table III. Number of initiator fragments and terminal methine proton per polymer and oligomer molecule of MMA- $d_{8}$ produced by $\mathrm{C}_{4} \mathrm{H}_{9} \mathrm{MgCl}$ in toluene

at $-78^{\circ} \mathrm{C}$ for $72 \mathrm{~h}$

\begin{tabular}{|c|c|c|c|c|}
\hline & 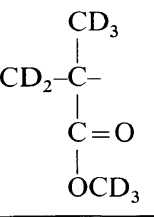 & $\begin{array}{c}\mathrm{CD}_{3} \\
\stackrel{\mathrm{CD}_{2}-\mathrm{C}-}{!} \\
\stackrel{\mathrm{C}=\mathrm{O}}{\mathrm{l}^{2}} \\
\mathrm{C}_{4} \mathrm{H}_{9}\end{array}$ & $\begin{array}{c}\mathrm{CD}_{3} \\
\mid \\
-\mathrm{CD}_{2}-\mathrm{C}-\mathrm{H} \\
\mid \mathrm{H} \\
\mathrm{C}=\mathrm{O} \\
\mathrm{l} \\
\mathrm{C}_{4} \mathrm{H}_{9}\end{array}$ & 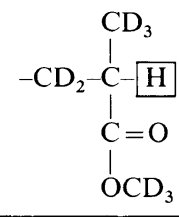 \\
\hline Polymer & 1.0 & 0.3 & 0.3 & 0.4 \\
\hline Oligomer & 1.0 & 0.4 & 0.4 & 0.4 \\
\hline
\end{tabular}

The content of the two types of terminal methine protons and the initiator fragments in the polymer and oligomer obtained by $\mathrm{C}_{4} \mathrm{H}_{9}$ $\mathrm{MgCl}$ was determined by the following procedure. Figure 3 depicts the carbonyl methylene and terminal methine proton region spectra of the polymers and oligomers of MMA- $d_{8}$ obtained in the $\mathrm{CH}_{3} \mathrm{OH}$ - and $\mathrm{CD}_{3} \mathrm{OD}$-terminated polymerizations by $\mathrm{C}_{4} \mathrm{H}_{9} \mathrm{MgCl}$ ( $c f$. Table I). When the polymerization mixture was quenched by $\mathrm{CD}_{3} \mathrm{OD}$ instead of $\mathrm{CH}_{3} \mathrm{OH}$, the signal at $2.57 \mathrm{ppm}$ almost disappeared, and the intensities of signals around $2.4 \mathrm{ppm}$ decreased to some extent (Figures 3C and 3D), reflecting termination by deuterium. ${ }^{* 3}$

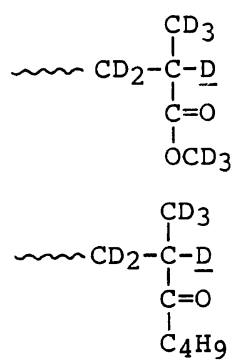

The signal at $2.40 \mathrm{ppm}$ in the spectra of Polymer-D/d and Oligomer-D/d is due only to the carbonyl methylene protons of BIPK- $d_{5}$ units. Table II summarizes the ${ }^{1} \mathrm{H}$ NMR signal intensities for methyl protons of butyl groups $(0.8 \mathrm{ppm})$, carbonyl methylene protons in BIPK- $d_{5}$ units combined with MMA-H ( $2.4 \mathrm{ppm})$, and BIPK-H (2.57 ppm); the intensities are expressed in terms of the hydrogen content per gram of a polymer or oligomer sample. Then, the difference in the signal intensity at $2.45 \mathrm{ppm}$ between Polymer-D/h and Polymer-D/d or Oligomer-D/h and Oligomer-D/d should correspond to the amount of MMA-H.

From the data in Tables I and II, the numbers per chain of BIPK-H, MMA-H, BIPK- $d_{5}$ unit, and $\mathrm{C}_{4} \mathrm{H}_{9}-$ groups at the $\alpha$-end was calculated as shown in Table III. ${ }^{* 4}$ Both the polymer and oligomer molecules contain one butyl group at the $\alpha$-end. The polymer molecule has 0.3 BIPK $-d_{5}$ unit and the same amount of BIPK-H. The oligomer has 0.4 BIPK $-d_{5}$ unit and also the same amount of BIPK-H. These values indicate that almost all the BIPK unit is located at the $\omega$-end of the chain.

In order to obtain additional evidence for

*3 A small signal remained at $2.57 \mathrm{ppm}$ in the spectra of Polymer-D/d and Oligomer-D/d (Figures 3C and 3D), even if the termination by $\mathrm{CD}_{3} \mathrm{OD}$ was performed with careful exclusion of moisture. An alternative source of the signal would be the carbonyl methylene protons of BIPK- $d_{5}$ units located in the middle of the chains. The carbonyl methylene protons of in-chain BIPK- $d_{5}$ units exhibit broad signals in this region, and they have a much shorter spin-lattice relaxation times $\left(T_{1}\right)$ that of BIPK- $\mathrm{H}^{16}$. In order to check this problem the ${ }^{1} \mathrm{H}$ NMR spectrum of Oligomer-D/d was recorded using a double pulse $\left(180^{\circ}-t-90^{\circ}\right)$ technique. However, no sign of the presence of in-chain BIPK- $d_{5}$ units was observed.

*4 The precision of hydrogen content determination was about $3 \%$ and that of molecular weight determination, $3-5 \%$. The precision of the results shown in Table III was thus estimated to be $6-8 \%$. 
the location of the ketone unit in the chain, the heptane-soluble fraction of undeuterated MMA oligomer prepared under the same conditions were fractionated by gel-permeation chromatography (GPC) (Figure 4), and fractions from the dimer to heptamer were collected. It was found by NMR and mass spectroscopies that all these fractions contained two types of oligomers, which contain one ketone unit at the $\omega$-end but none in the chain, respectively.

Figure 5 shows the FD- and the EI-mass spectra of the trimers. The FD-spectrum (Figure 5A) indicates that fraction $3 a$ is the trimer containing one ketone unit in the chain, and the EI-spectrum (Figure 5B) indicates the presence of the ketone unit at the $\omega$-end. Peaks at $\left(\mathrm{M}^{+} / e\right)=384,257,227,157$, and 127 correspond to the fragments shown below.

\begin{tabular}{ccc}
\hline $\mathrm{M}^{+} / e$ & \multicolumn{2}{c}{ Fragment } \\
\hline 384 & {$\left[\mathrm{C}_{4} \mathrm{H}_{9}-(\mathrm{MMA})-(\mathrm{MMA})-(\mathrm{BIPK})-\mathrm{H}\right]^{+}$} \\
257 & {$\left[\mathrm{C}_{4} \mathrm{H}_{9}-(\mathrm{MMA})-(\mathrm{MMA})\right]^{+}$} \\
227 & \multicolumn{2}{c}{$[\text { (MMA)-(BIPK)-H }]^{+}$} \\
157 & {$\left[\mathrm{C}_{4} \mathrm{H}_{9}-(\mathrm{MMA})\right]^{+} \quad$} \\
127 & & {$[(\mathrm{BIPK})-\mathrm{H}]^{+}$} \\
\hline
\end{tabular}

No fragments which would come from the trimer $\mathrm{C}_{4} \mathrm{H}_{9}$-(MMA)-(BIPK)-(MMA)-H or $\mathrm{C}_{4} \mathrm{H}_{9}$-(BIPK)-(MMA)-(MMA)-H were observed in the spectrum.

\begin{tabular}{cl}
\hline $\mathrm{M}^{+} / e$ & \multicolumn{1}{c}{ Fragment } \\
\hline 283 & {$\left[\mathrm{C}_{4} \mathrm{H}_{9}-(\mathrm{MMA})-(\mathrm{BIPK})\right]^{+}$} \\
183 & {$\left[\mathrm{C}_{4} \mathrm{H}_{9}-(\mathrm{BIPK})\right]^{+}$} \\
\hline
\end{tabular}

Figure $5 \mathrm{C}$ is the FD-mass spectrum of fraction 3b. The spectrum shows that the fraction is the MMA trimer without a ketone unit in the chain. Similar results were obtained on the tetramer, pentamer, hexamer, and heptamer. The results clearly indicate that there are two types of oligomers ending with the MMA and BIPK units, respectively.

\section{Cyclic $\beta$-Ketoester Unit and Other Structures at the Chain Ends ( $\omega$-ends)}

So long as we consider that the polymer and oligomer molecules have linear and nonbranched chain structures, each molecule should have one $\alpha$-end and one $\omega$-end. However, the sum total of MMA-H and BIPK-H per polymer or oligomer molecule shown in Table III does not amount to unity, and this suggests the presence of other types of structure at the $\omega$-end of the chain.

Goode et al. ${ }^{10}$ reported that the principal mode of termination in the polymerization of MMA by phenylmagnesium bromide in toluene at $0^{\circ} \mathrm{C}$ is intramolecular cyclization to yield a $\beta$-ketoester at the chain end.

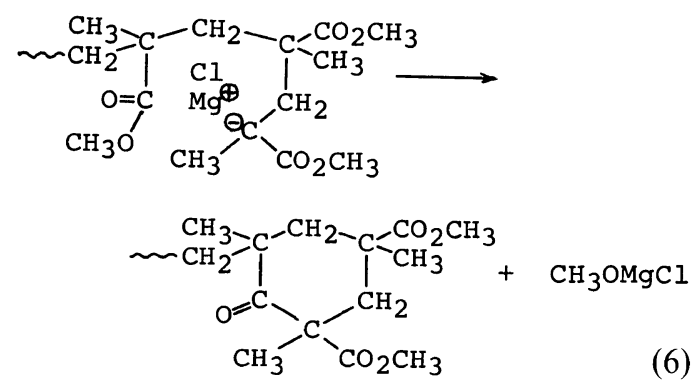

Recently, two of the present authors (K.U. and K.H.) carried out the cyclization of the propagating anion of PMMA, and studied the structure of the resulting cyclic $\beta$-ketoester unit by ${ }^{13} \mathrm{C}$ NMR and IR spectroscopies. The cyclic $\beta$-ketoester unit at the $\omega$-end of PMMA exhibited characteristic NMR signals at $173.3-173.9 \mathrm{ppm}$ and $177.5-178.5 \mathrm{ppm}$ for ester carbonyl carbons, and at $211-212 \mathrm{ppm}$ for ketone carbonyl carbons. These signals were found to be sensitive to the stereostructure of the ketoester ring. ${ }^{24}$ As shown in Figure 6, Oligomer- $\mathrm{H} / \mathrm{h}$ shows the characteristic signals of ester carbonyl carbons of cyclic ketone units at $173.3 \mathrm{ppm}$ and $173.6 \mathrm{ppm}$. Intensity measurements indicated that about $5 \%$ of the oligomer contained the cyclic $\beta$ ketoester unit at the chain end.

In order to find other structures at the $\omega$ ends, ${ }^{1} \mathrm{H}$ NMR spectra of the oligomers were 


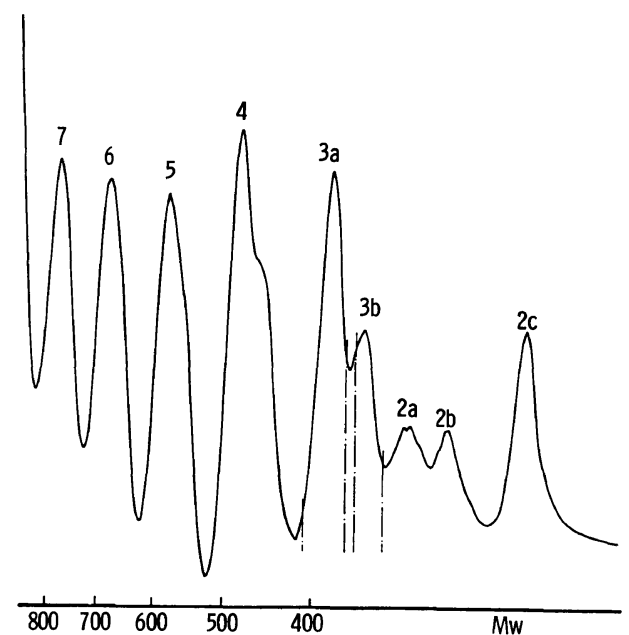

Figure 4. GPC chromatogram of the heptane-soluble fraction of MMA oligomer prepared by $\mathrm{C}_{4} \mathrm{H}_{9} \mathrm{MgCl}$ in toluene at $-78^{\circ} \mathrm{C}$. Eluent: chloroform, Column: polystyrene-gel (maximum porosity 3000 ). Recycled three times. examined in detail. In the ${ }^{1} \mathrm{H}$ NMR spectrum of the undeuterated oligomer obtained by polymerization at $-78^{\circ} \mathrm{C}$ for $72 \mathrm{~h}$, three weak multiplets were observed in the region of vinyl proton signal at 4.87, 4.97, and 5.08 ppm (Figure 7A). It was expected that dibutylisopropenylcarbinol ${ }^{* 5}$ was formed by the reaction of BIPK and the initiator and contained in the oligomer.<smiles>C=C(C)C(=O)CCCCCCCCCCCCCCCC</smiles>

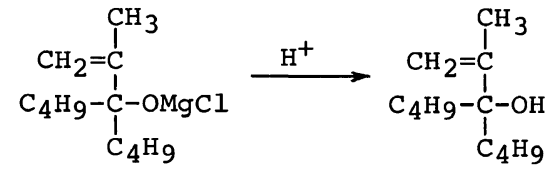

The authentic sample for this alcohol showed a pair of signals at 4.87 and $4.97 \mathrm{ppm}$ due to the
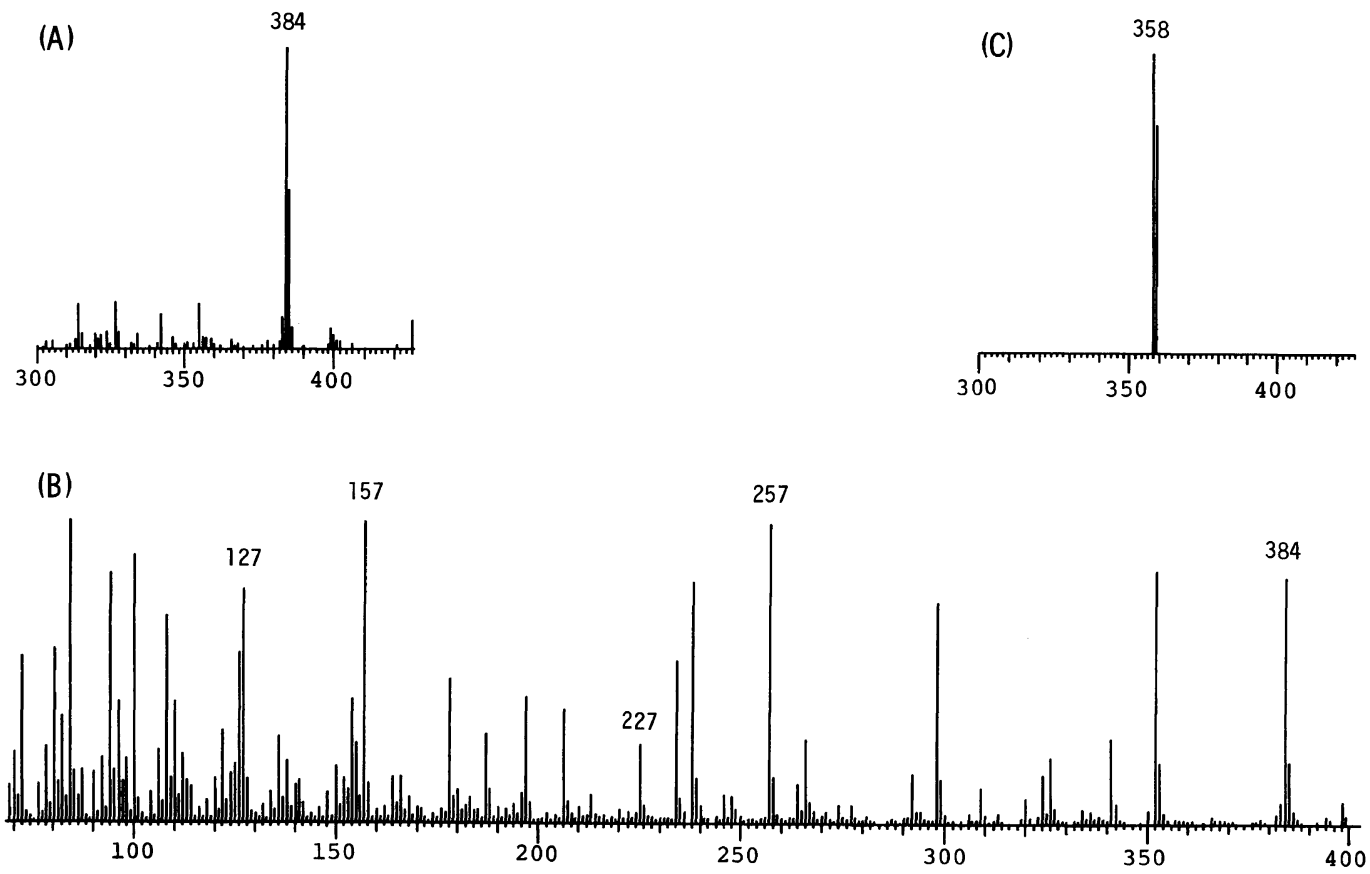

Figure 5. FD- and EI-mass spectra of the trimers ended with BIPK unit (A), (B), and MMA units (C) prepared by $\mathrm{C}_{4} \mathrm{H}_{9} \mathrm{MgCl}$ in toluene at $-78^{\circ} \mathrm{C}$.

*5 3-Butyl-2-methyl-1-hepten-3-ol, according to IUPAC nomenclature. 


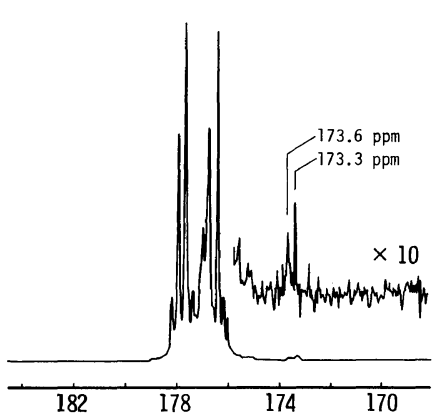

Figure 6. ${ }^{13} \mathrm{C}$ NMR spectrum of the oligo(MMA) prepared by $\mathrm{C}_{4} \mathrm{H}_{9} \mathrm{MgCl}$ in toluene at $-78^{\circ} \mathrm{C}$ (Oligomer$\mathrm{H} / \mathrm{h})$.

vinyl protons, and the signal due to the methyl protons of the isopropenyl group at $1.69 \mathrm{ppm}$. As shown in Figure 7B, the signals in the vinyl proton region of the oligomer changed into two pairs of typical AB quartets when irradiated around $1.7 \mathrm{ppm}$ the region for the signal of the methyl protons of the isopropenyl group. The quartets at 4.87 and 4.97 ppm were assigned to the vinyl protons of dibutylisopropenylcarbinol included in the oligomer. The other quartets at 4.97 and $5.08 \mathrm{ppm}$ should be due to a similar isopropenyl compound because of the similarities of the chemical shifts. The spin-lattice relaxation time, $T_{1}$, for the signal at $5.08 \mathrm{ppm}$ was $2.3 \mathrm{~s}$, which was significantly shorter than that for the signal at $4.87 \mathrm{ppm}(4.4 \mathrm{~s})$. The results enabled us to assign the quartets at 4.97 and $5.08 \mathrm{ppm}$ to the vinyl protons of the tertiary alcoholic $\omega$-end formed through the addition of the propagating chain end onto the carbonyl group of BIPK.
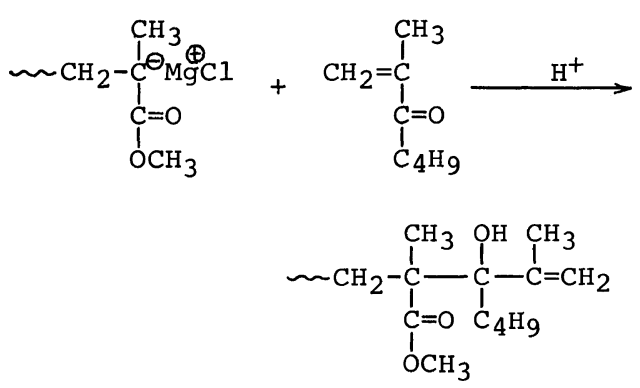
Table IV. Structure of the $\omega$-ends of the polymerization products of MMA prepared by $\mathrm{C}_{4} \mathrm{H}_{9} \mathrm{MgCl}$ in toluene at $-78^{\circ} \mathrm{C}$ for $72 \mathrm{~h}$

\begin{tabular}{|c|c|c|}
\hline & Oligomer & Polymer \\
\hline 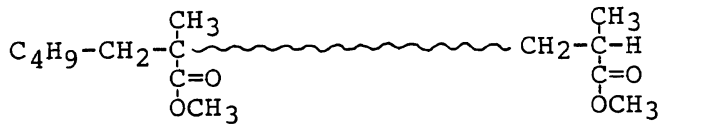 & $40 \%$ & $40 \%$ \\
\hline 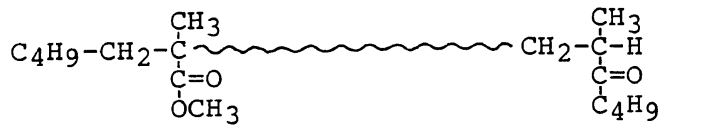 & $40 \%$ & $30 \%$ \\
\hline 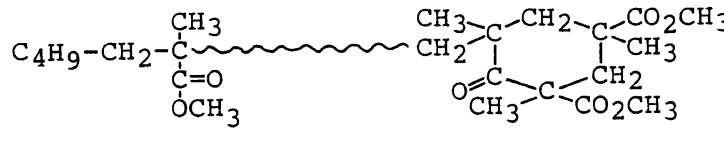 & $5 \%$ & - \\
\hline 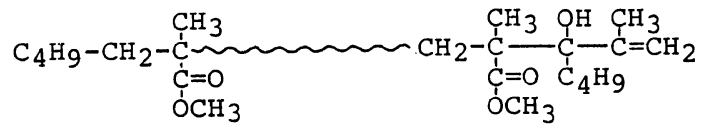 & $4 \%$ & - \\
\hline 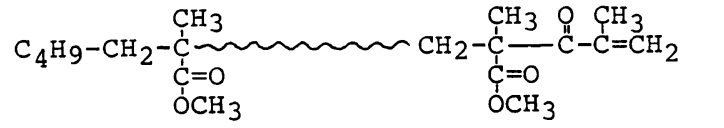 & $1 \%$ & - \\
\hline
\end{tabular}

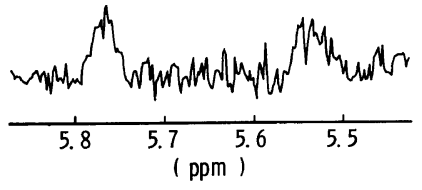

Figure 8. ${ }^{1} \mathrm{H}$ NMR spectrum of vinyl protons in oligo(MMA) prepared by $\mathrm{C}_{4} \mathrm{H}_{9} \mathrm{MgCl}$ in toluene at $-78^{\circ} \mathrm{C}$ for $72 \mathrm{~h}$.

$\omega$-ends of polymer and oligomer described above. The structures of chain ends of about $90 \%$ oligomer molecules were clarified. The cyclic $\beta$-ketoester structure ( $c f$. (6)), tertiary alcoholic structure ( $c f$. (8)) and linear $\beta$ ketoester structure ( $c f$. (9)) may also be present in polymer molecules, but they have not been detected, probably owing to the lower intensities of the NMR signals.

\section{DISCUSSION}

It is well known that in the polymerization of methacrylates by Grignard reagents, all the initiator used cannot be accounted for if each
Table V. Fate of initiator fragments in the polymerization of MMA in toluene at $-78^{\circ} \mathrm{C}$ for $72 \mathrm{~h}$ (percentage based on $\mathrm{C}_{4} \mathrm{H}_{9} \mathrm{MgCl}$ used)

\begin{tabular}{|c|c|c|}
\hline $\mathrm{C}_{4} \mathrm{H}_{9} \mathrm{Mg}-$ & (Unreacted) & 18 \\
\hline $\mathrm{CH}_{2}=\stackrel{\mathrm{CH}_{3}}{\mathrm{C}}-\mathrm{COC}_{4} \mathrm{H}_{9}$ & (Unreacted) & 8 \\
\hline $\mathrm{CH}_{2}=\stackrel{\mathrm{C}}{\mathrm{C}} \stackrel{\mathrm{H}_{3}}{=} \stackrel{\mathrm{OH}}{\mathrm{C}}\left(\mathrm{C}_{4} \mathrm{H}_{9}\right)_{2}$ & & 6 \\
\hline $\mathrm{C}_{4} \mathrm{H}_{9}-\mathrm{CH}_{2}-{\stackrel{\mathrm{C}_{2}}{\mathrm{CO}_{2} \mathrm{CH}_{3}}}_{\mathrm{CH}_{3}}^{\mathrm{C}_{3}}$ & $\left\{\begin{array}{l}(\text { Polymer })^{\mathrm{a}} \\
(\text { Oligomer })^{\mathrm{a}}\end{array}\right.$ & $\begin{array}{r}7 \\
33\end{array}$ \\
\hline 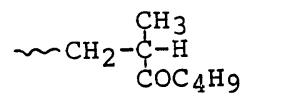 & $\left\{\begin{array}{l}(\text { Polymer })^{\mathrm{a}} \\
(\text { Oligomer })^{\mathrm{a}}\end{array}\right.$ & $\begin{array}{r}2 \\
16\end{array}$ \\
\hline \multirow{2}{*}{ 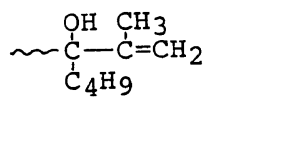 } & $\left\{\begin{array}{l}(\text { Polymer }) \\
(\text { Oligomer })\end{array}\right.$ & - \\
\hline & Total & $91 \%$ \\
\hline
\end{tabular}

a Data refer to the polymerization of MMA- $d_{8}$.

polymer or oligomer molecule is assumed to contain one initiator fragment. In this study, 
we found that some of the polymer or oligomer molecules contained two initiator fragments, one at the $\alpha$-end and the other at the $\omega$ end as a ketone unit. The sum total of the butyl groups in the polymer and oligomer chain was $60 \%$ of the initiator used (Table V). About $20 \%$ of the initiator remained unreacted during the polymerization and was recovered as butane when the polymerization was terminated. Bateup and Allen ${ }^{12}$ observed similar amounts of unreacted $\mathrm{C}_{4} \mathrm{H}_{9} \mathrm{MgBr}$ in the polymerization in toluene-THF mixtures. They suggest that the unreacted $\mathrm{C}_{4} \mathrm{H}_{9} \mathrm{Mg}-$ species coordinate with the active center affecting the stereoregulation. The $\mathrm{C}_{4} \mathrm{H}_{9}-$ groups in the unreacted BIPK and dibutylisopropenylcarbinol corresponded to 8 and $6 \%$ of the $\mathrm{C}_{4} \mathrm{H}_{9}$ $\mathrm{MgCl}$ used, respectively. Thus, most of the initiator fragments are accounted for (Table V).

From the results mentioned in the previous section, it is concluded that in the polymerization of $\mathrm{MMA}$ by $\mathrm{C}_{4} \mathrm{H}_{9} \mathrm{MgCl}$ the initiator attacks both the vinyl and carbonyl double bonds during the initiation process. Attack on the vinyl group forms the initiating species.<smiles>C=C(C)C(=O)OC</smiles>

Attack on the carbonyl double bond gives an alkoxide, which forms BIPK with a release of

methoxymagnesium chloride.<smiles>C=C(C)C(=O)OC</smiles>

BIPK is more reactive than MMA as evident from the $Q$ and $e$ values $(Q=1.07, e=0.86)^{16}$ higher than those of MMA $(Q=0.74, e=$ $0.40)^{26}$ and as a result, some of the propagating species are attacked by BIPK. The result- ing species ending with a BIPK unit is less reactive than that ending with an MMA unit, and remains unreacted during the polymerization (12).

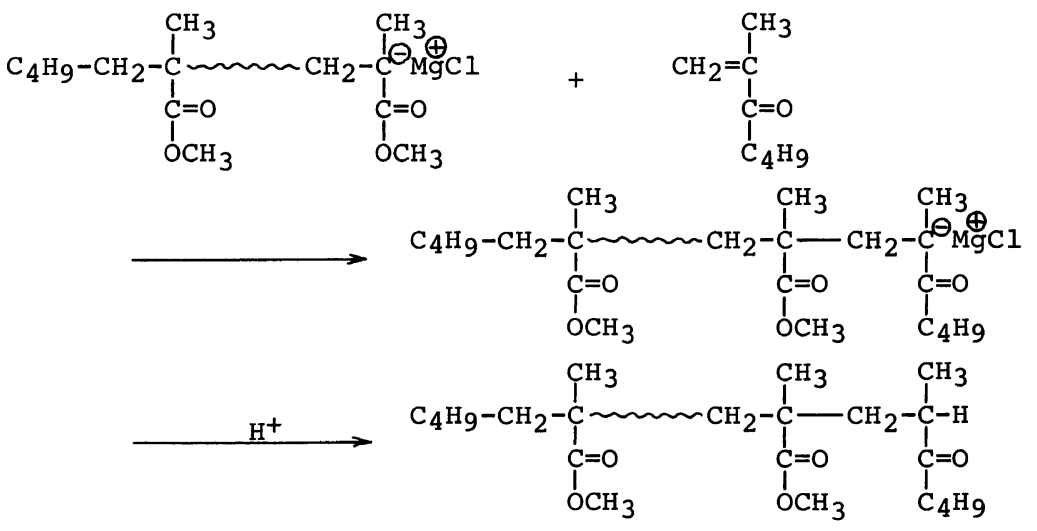


This is the reason why almost all the BIPK units are located at the chain ends of the polymer or oligomer molecules. Thus, participation of BIPK in the polymerization should make the molecular weight distribution broad.

In the polymerization of MMA by $\mathrm{C}_{4} \mathrm{H}_{9} \mathrm{Li}$ in toluene, the carbonyl addition of the initiator to the monomer also takes place. and incorporation of the resulting BIPK into the polymer and oligomer of MMA was demonstrated by the totally deuterated monomer method. ${ }^{15}$ In the polymerization by $\mathrm{C}_{4} \mathrm{H}_{9} \mathrm{Li}$, the polymer began to form after all the BIPK in the system was consumed, while in the polymerization by $\mathrm{C}_{4} \mathrm{H}_{9} \mathrm{MgCl}$, unreacted BIPK was detected after completion of the polymerization. This difference may be attributable to the stabilities of lithium (13) and magnesium alkoxides (14) formed through the attack of initiators on the carbonyl group of MMA.

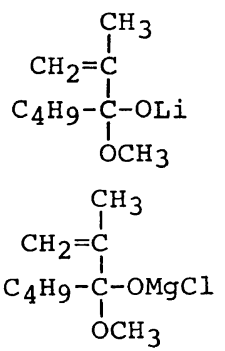

The $\mathrm{MgCl}$ salts of the alkoxide would be more stable than the corresponding $\mathrm{Li}$ salts, and some of them would not release methoxymagnesium chloride $\left(\mathrm{CH}_{3} \mathrm{OMgCl}\right)$ immediately but rather on termination of the reaction to form BIPK.

PMMA prepared by $\mathrm{C}_{4} \mathrm{H}_{9} \mathrm{MgCl}$ in toluene at $-78^{\circ} \mathrm{C}$ is a mixture of isotactic and syndiotactic polymers (Table I). The coexistence of propagating species with different stereospecificity and activity is demonstrated for the polymerizations of methacrylates with organomagnesium compounds. ${ }^{6-8,27,28}$ This phenomenon has been ascribed to the Schlenk equilibrium of initiators, ${ }^{6-8}$ coordination of magnesium and ether compounds to active centers, ${ }^{6-8}$ and stereocomplex formation during the polymerization. ${ }^{27}$ In the polymerization of ethyl methacrylate by butyllithium in toluene, the multiplicity of active species is caused by the formation of lithium ethoxide in the initiation process, and the propagating species coordinated with the ethoxide forms a syndiotactic polymer while the species free from the alkoxide forms an isotactic one. ${ }^{17}$ In the polymerization by $\mathrm{C}_{4} \mathrm{H}_{9} \mathrm{MgCl}, \mathrm{CH}_{3} \mathrm{OMgCl}$ should be formed through the carbonyl addition of the initiator to MMA (11) and the intramolecular cyclization (6). The presence of $\mathrm{CH}_{3} \mathrm{OMgCl}$ may be one of the factors causing the coexistence of isotactic-flavoring and syndiotactic-favoring propagating species. Regarding this problem, we are now examining the chemical structure ${ }^{29}$ of syndiotactic P(MMA$\left.d_{8}\right)$ and isotactic $\mathrm{P}\left(\mathrm{MMA}-d_{8}\right)$ obtained by the polymerization with $\mathrm{C}_{4} \mathrm{H}_{9} \mathrm{MgCl}$ followed by fractionation using the competitive adsorbtion method, ${ }^{30}$ and we are also studying the effects of ether ${ }^{31}$ and BIPK on the polymerization. The results will be published in the near future.

If there occurs no carbonyl addition of the initiator to the monomer, highly stereoregular PMMA with a narrow molecular distribution should be formed. Recently, it was found that the polymerization of MMA by $t-\mathrm{C}_{4} \mathrm{H}_{9} \mathrm{MgBr}$ gave highly isotactic (I $>98 \%$ ) PMMA with a narrow molecular weight distribution $\left(M_{w} /\right.$ $\left.M_{n}<1.2\right)$, where the initiator scarcely attacked the carbonyl group of the monomer. ${ }^{23}$

A termination reaction in the polymerization of MMA by phenylmagnesium bromide at $0^{\circ} \mathrm{C}$ occurred predominantly through intramolecular cyclization to yield a cyclic $\beta$ ketoester at the chain end. ${ }^{10}$ In the present work it was found that only $5 \%$ of the oligomer formed at $-78^{\circ} \mathrm{C}$ contains the cyclic $\beta$ ketoester unit at the $\omega$-end of the chain, although the percentage increased to $60 \%$ when the polymerization was carried out at $0^{\circ} \mathrm{C}^{24}$ These results indicate that termination by intramolecular cyclization does not play an im- 
portant role in the polymerization by $\mathrm{C}_{4} \mathrm{H}_{9}$ $\mathrm{MgCl}$ at low temperature.

\section{REFERENCES}

1. W. E. Goode, F. H. Owens, R. P. Fellman, W. H. Snyder, and J. E. Moore, J. Polym. Sci., 46, 317 (1960).

2. A. Nishioka, H. Watanabe, K. Abe, and I. Sono, $J$. Polym. Sci., 48, 241 (1960).

3. P. Pino and U. W. Suter, Polymer, 17, 977 (1976).

4. H. Yuki and K. Hatada, Adv. Polym. Sci., 31, 1 (1979).

5. B. L. Erussalimsky, E. Yu. Melenevskaya, and.V. N. Sgonnik, Acta Polymerica, 32, 183 (1981).

6. P. E. M. Allen and B. O. Bateup, Eur. Polym. J., 14, 1001 (1978).

7. P. E. M. Allen and C. Mair, Eur. Polym. J., 20, 697 (1984).

8. K. Matsuzaki, H. Tanaka, and T. Kanai, Makromol. Chem., 182, 2905 (1981).

9. P. E. M. Allen, C. Mair, D. R. G. Williams, and E. H. Williams, Eur. Polym. J., 20, 119 (1984).

10. W. E. Goode, F. H. Owens, and W. L. Myers, $J$. Polym. Sci., 47, 75 (1960).

11. Y. Yasuda, N. Kawabata, and T. Tsuruta, $J$. Macromol. Sci.-Chem., A1, 669 (1967).

12. B. O. Bateup and P. E. M. Allen, Eur. Polym. J., 13, 761 (1977).

13. K. Hatada, T. Kitayama, and H. Yuki, Makromol. Chem., Rapid Commun., 1, 51 (1980).

14. K. Hatada, T. Kitayama, and H. Yuki, Polym. Bull., 2, 15 (1980).

15. K. Hatada, T. Kitayama, K. Fujikawa, K. Ohta, and
H. Yuki, ACS Symp. Ser., 166, 327 (1981).

16. K. Hatada, T. Kitayama, S. Okahata, and H. Yuki, Polym. J., 13, 1045 (1981).

17. K. Hatada, T. Kitayama, S. Okahata, and H. Yuki, Polym. J., 14, 971 (1982).

18. T. Kitayama, K. Ute, and K. Hatada, Polym. J., 16, 925 (1984).

19. S. C. Watson and J. F. Eastham, J, Organometal. Chem., 9, 165 (1967).

20. K. Hatada, Y. Terawaki, and H. Okuda, Org. Magn. Res., 9, 518 (1977).

21. D. M. Wiles and S. Bywater, Trans. Faraday Soc., 61, 150 (1965).

22. K. Hatada, T. Kitayama, H. Sugino, and Y. Umemura, Polym. J., 12, 535 (1980).

23. K. Hatada, K. Ute, K. Tanaka, T. Kitayama, and Y. Okamoto, Polym. J., 17, 977 (1985).

24. K. Ute and K. Hatada, Polym. J., to be submitted.

25. H. Schreiber, Makromol. Chem., 36, 86 (1960).

26. G. E. Ham, "Copolymerization," John Wiley \& Sons Inc., New York., N. Y., 1964, p. 845.

27. T. Miyamoto, and H. Inagaki, Polym. J., 1, 46 (1970).

28. K. Hatada, T. Kitayama, H. Sugino, M. Furomoto, and H. Yuki, "Preparation and Properties of Stereoregular Polymers," R. W. Lenz and F. Ciardelli, Ed., D. Reidel Publishing Company, Dordrecht, Holland, 1979, p 185.

29. K. Hatada, K. Ute, and T. Kitayama, Polym. Prepr. Jpn., 32, 1459 (1983).

30. T. Miyamoto, S. Tomoshige, and H. Inagaki, Polym. .J., 6, 564 (1974).

31. K. Hatada, K. Ute, T. Kitayama, and M. Kamachi, Polym. J., 15, 771 (1983). 